Proceedings

\title{
Peak Compression Force Physics in Rugby Union Scrum ${ }^{+}$
}

\author{
Benjamin Lallemand 1,2,*, Christophe Clanet ${ }^{2}$, Sylvain Blanchard 1, Patricio Noriega ${ }^{1}$, \\ Julien Piscione ${ }^{3}$, Olivier Chaplain ${ }^{3}$, Didier Retière ${ }^{3}$ and Caroline Cohen ${ }^{2}$ \\ 1 Racing 92, 92350 Le Plessis-Robinson, France; sylvain.blanchard@racing92.fr (S.B.); \\ patricio.noriega@racing92.fr (P.N.) \\ 2 LadHyX, Ecole polytechnique, 91120 Palaiseau, France; christophe.clanet@ladhyx.polytechnique.fr (C.C.); \\ caroline.cohen@ladhyx.polytechnique.fr (C.C.) \\ 3 French Rugby Federation, Centre National de Rugby, 91460 Marcoussis, France; \\ Julien.PISCIONE@ffr.fr (J.P.); olivier.chaplain@ffr.fr (O.C.); Didier.RETIERE@ffr.fr (D.R.) \\ * Correspondence: benjamin.lallemand@racing92.fr \\ † Presented at the 13th conference of the International Sports Engineering Association, Online, 22-26 June 2020. \\ Published: 15 June 2020
}

\begin{abstract}
Scrums play a major role in Rugby Union games, and are historically known as a showdown between the two packs of opposing teams, composed of their eight forwards players organized in a 3-4-1 configuration, respectively. We investigate scrum mechanics by working with professional male forward players from Racing 92, a high-level French Rugby club, and measuring the forces they apply on the French Rugby Federation instrumented scrum machine. Signal analysis reveals two major phases in the force production during a scrummaging effort: an impulsive engagement force, and then a force sustained for a few seconds. We experimentally compare individual performances of the engagement phase. We discuss the influence of the mass and the engagement speed of the players, and we introduce the model we are investigating to describe the individual impact on a scrum machine. We expect this model to be the elementary component of a collective model of a pack.
\end{abstract}

Keywords: rugby union scrum; peak compression force; mass-spring-damper model

\section{Introduction}

In Rugby Union, the 'scrum' is a trial of strength and a strategic opposition between the two teams' eight forwards. These two packs, pushing against each other, are composed of three rows, in a 3-4-1 configuration, as shown in Figure 1a. Nowadays, a scrum is directed by the Crouch-Bind-Set (CBS) referee's calls [1]:

- "Crouch" - front rows are crouching to face the opponents at the same height;

- "Bind" - each prop binds to her/his opponent who is in front of her/him;

- "Set" - when both sides are stable, packs engage.

Then, when the scrum is stable again, the scrum-half introduces the ball between the two packs, and the pushing phase follows.

The scrum is an important part of a rugby game that has constantly changed throughout decades. The last thirty years' evolution results from studies made in order to reduce the number of spine injuries [2-4]. Until the nineties, front row players were starting to engage in a standing position really far from each other (more than $2 \mathrm{~m}$ ), as we can see in Figure 1b. Then, the rows started to crouch before engaging, but the space between the first rows remained large (more than 1 meter) until mid2000s, as we observe in Figure 1c. Then, with the introduction of a touch phase, we observed a tendency to put the first rows closer to each other before the engagement. Nowadays, front rows are 
practically touching opponents with their heads (cf. Figure 1d). Milburn [5] described engagement force as an impulsive force that becomes larger with higher front rows' engagement speed and larger player's weight. As the mass of rugby forwards increased of $26 \%$ through these last forty years [6,7], we show in Table 1 the correlation between pack's weight increase and engagement compression force $F_{\text {peak }}$ (expressed in kilogram-force), from $800 \mathrm{~kg}$ in the nineties to $1600 \mathrm{~kg}$ in the $2010 \mathrm{~s}$.

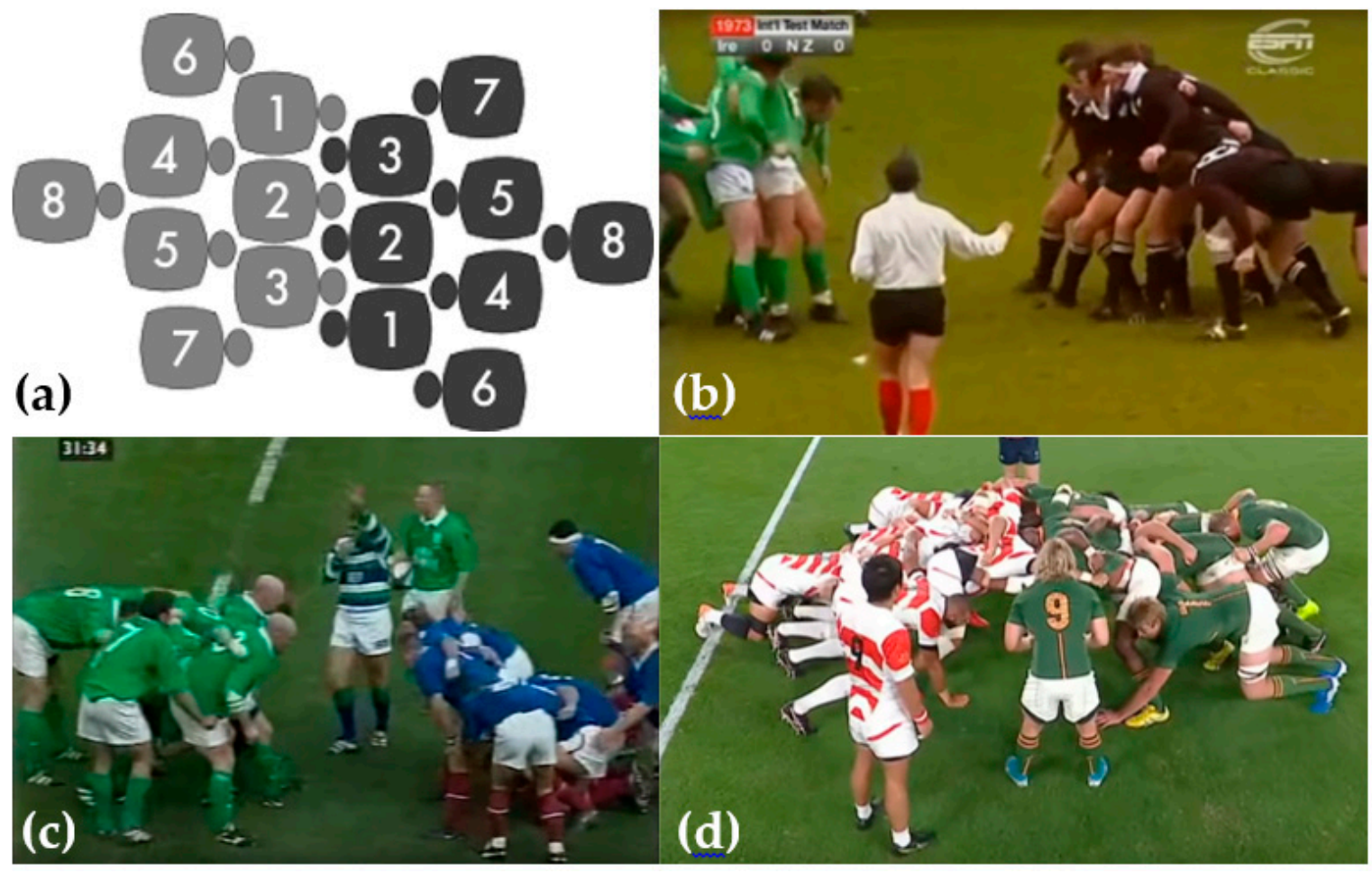

Figure 1. Scrum engagement phase evolution through time. (a) Configurational scheme of a scrum with player's numbers corresponding to their positions. (b) Snapshot of a scrum in 1973, Ireland vs New Zealand, Test match. Front rows are in standing positions and separated by 2-3 m. (c) Scrum in 2000, Ireland vs France, Six Nations 2000. The apparition of first rows crouching, space between front rows remains big. (d) A scrum in 2019, Japan vs South Africa, World Cup 2019. A modern scrum with actual CBS referee's calls. Before the engagement, front rows are binding with each other and the space between them is really reduced compared to older scrums.

Table 1. Pack weight and peak compression force evolution.

\begin{tabular}{|c|c|c|c|}
\hline $\begin{array}{c}\text { Year of Publication, } \\
\text { Pack Level }\end{array}$ & $\begin{array}{c}1990[5], \\
\text { International }\end{array}$ & $\begin{array}{c}2000[8], \\
\text { Community }\end{array}$ & 2015 [9], International \\
\hline$F_{\text {peak }}(\mathrm{kg})$ & 814 & $12.3 \times 10^{2}$ & $\begin{array}{ll}\text { CTPE: } & 16.8 \times 10^{2} ; \text { CTS: } 16.8 \times \\
& 10^{2} ; \text { FoldIn: } 878\end{array}$ \\
\hline Pack weight $(\mathrm{kg})$ & $686^{* *}$ & $774 * *$ & 893 \\
\hline
\end{tabular}

** Pack weight reconstructed with players' average mass.

The second main parameter involved in $F_{\text {peak }}$ magnitude is engagement speed. This influence of impact speed is represented in the last column of Table 1 with data from [9] for a pack using different engagement techniques. CTPE refers to Crouch-Touch-Pause-Engage 2011/2012 engagement process, CTS refers to Crouch-Touch-Set 2012/2013 engagement process, and FoldIn consists in a CTPE process with an instruction given to the players to not generate momentum before the scrum machine's contact. In this latter case, the impact speed is reduced a lot thanks to space reduction between front rows, and so $F_{\text {peak }}$ too $[9,10]$. Thus, the referee's calls are here to reduce peak compression force in the engagement phase by reducing the space, and so speed between front rows [11]. 
We conducted an experimental study with professional rugby players to study force production and transmission in scrums. After introducing the experimental setup, we show the individual peak compression forces obtained and discuss the results in terms of the influence of engagement speed. Finally, we investigate a mass-spring-damper (MSD) model to learn about players' parameters through impact force analysis.

\section{Experimental Study}

"L'Atelier de la mêlee" is the instrumented scrum machine of the French National team we used to conduct our experiments thanks to the French Rugby Federation. This tool is able to simulate an adverse pack and to measure simultaneously the different forces applied to it $[12,13]$. The experimental setup is shown in Figure 2a. In our study, we only focus on compression force which corresponds to the force developed along the scrum's main axis $x$, defined in Figure 2a. We studied individually 11 professional forward players of Racing 92 (mean mass $=117 \pm 14 \mathrm{~kg}$ ). Each player volunteered and signed an informed consent form. Players were asked to adopt a position that corresponds to the one they have in a complete scrum. They first impacted the scrum machine in the same way they are doing during a complete scrum engagement phase, and after a coach instruction, were asked to produce three seconds of maximal effort push.

\section{Results}

An example of individual experiment is featured in Figure 2. In Figure 2a, we show a snapshot from the zenithal and side point of view of a Number- 5 lock's experiment. Figure $2 b$ shows the time evolution associated compression force. There are two interesting phases on the curve: the engagement phase which enables us to define $F_{\text {peak }}$, and a second phase with a plateau at an average value $F_{\text {mean }}$.

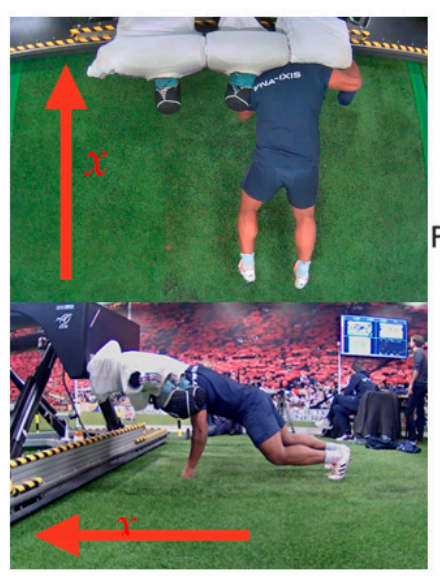

(a)

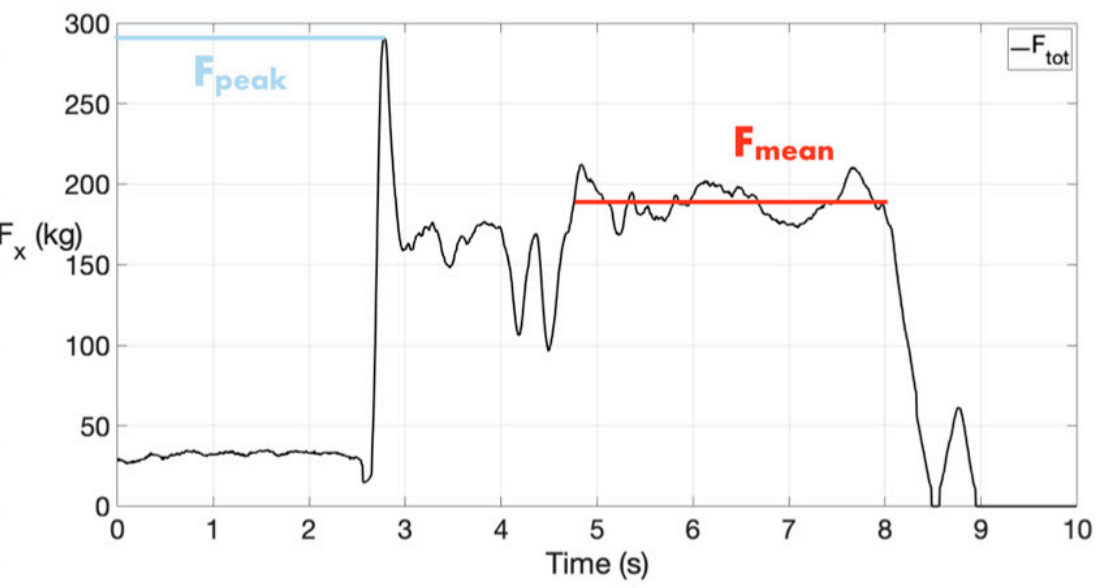

(b)

Figure 2. Example of a single player pushing against the scrum machine. (a) Zenithal and side view of Number-5 lock experiment. (b) Compression force in function of time. $F_{\text {peak }}$ is defined as the maximal value reached during the engagement. $F_{\text {mean }}$ is given by the higher averaging of the force made with a window of 1.8 seconds on the plateau.

In Figure $2 b$, between these two phases (from $t=4 \mathrm{~s}$ and $t=5 \mathrm{~s}$ ), we observe twice a $30 \%$ decrease of force, which correspond on the synchronized video to the moments when the player moves his feet. In Table 2, we sum up the $F_{\text {mean }}$ individual results. We see that, on average, hookers and tighthead props are the players that can develop the higher forces. In Table 3, we gather the individual $F_{\text {peak }}$ results. For each player, we determine the initial speed of engagement by manual tracking on the video. It corresponds to the speed reached by the players are reaching when they hit the scrum machine. 
Table 2. Individual mean forces on the scrum machine.

\begin{tabular}{cccccc}
\hline $\begin{array}{c}\text { Position (Number of } \\
\text { Players) }\end{array}$ & $\begin{array}{c}\text { Loosehead } \\
\text { Props * (2) }\end{array}$ & $\begin{array}{c}\text { Hookers Tighthead } \\
\text { Props (3) }\end{array}$ & Locks (3) & Flankers * (2) & Number-8 (1) \\
\hline Weight $(\mathrm{kg})$ & $112 \pm 4.0$ & $119 \pm 18$ & $127 \pm 15$ & $110 \pm 4.0$ & 108 \\
$F_{\text {mean }}(\mathrm{kg})$ & $182 \pm 20$ & $201 \pm 25$ & $194 \pm 5.7$ & $174 \pm 52$ & 186 \\
\hline
\end{tabular}

* They only push with one shoulder.

Table 3. Individual peak compression force and engagement speed on the scrum machine.

\begin{tabular}{ccccccc}
\hline Player's Position & Lock-5 & Lock-4 & Hooker & Number-8 & Hooker 2 & Tight-Head Prop \\
\hline Engagement speed $\left(\mathrm{m} \cdot \mathrm{s}^{-1}\right)$ & 1.2 & 1.4 & $1.1 / 1.7$ & 1.9 & 2.2 & 3 \\
$F_{\text {peak }}(\mathrm{kg})$ & 271 & 466 & $285 / 331$ & 347 & 363 & 417 \\
\hline
\end{tabular}

In this table, we only chose the players who are pushing with two shoulders in order to have an equivalent surface of contact. We observe the higher the engagement speed, the higher $F_{\text {peak }}$ results (excluding locks results) are.

\section{MacMahon Look-Alike Model for a Single Player and Discussion}

In this section, we propose a model inspired from the MacMahon's model for muscle [14] to simulate a player that hits a scrum machine. We are focusing our study on the impact phase. We introduce the schematic drawing of the model in Figure 3a. We consider that the scrum machine is not moving. The player is modelized by a mass $m$, a spring of stiffness $k$, a damper of damping coefficient $\beta$ and a force generator $F_{0}$. We define $x_{1}$ and $x_{2}$ in Figure 3a such that the player's total length $x$ is given by

$$
x(t)=x_{1}(t)+x_{2}(t)
$$

and the force $F$ the player is applying on the scrum machine can be expressed as

$$
F(t)=k\left(x_{2}(0)-x_{2}(t)\right) .
$$

In Figure 3a, we represent the system at $t=0$ when the player hits the scrum machine with an initial speed $v_{0}$. The force model equations can be written as

$$
\frac{m}{k} \ddot{F}(t)+\frac{\beta}{k} \dot{F}(t)+F(t)=F_{0}-m \ddot{x}(t)-\beta \dot{x}(t) .
$$

For a simplification purpose, we use the approximation $\dot{x}(t)=0$, that signifies player's length does not change during the impact: player is staying on his feet. By nondimensionalization of Equation (3), we simplify the force model equation by introducing a dimensionless parameter $\mathrm{A}=\frac{m k}{\beta^{2}}$. Dimensionless force $\bar{F}$ equation derived from Equation (3) can now be written as

$$
A \ddot{\bar{F}}(t)+\dot{\bar{F}}(t)+\bar{F}(t)=1 \text {. }
$$

An individual attempt on the scrum machine is fully described by $A, \dot{\bar{F}}(0)=\frac{\beta v_{0}}{F_{0}}$ and Equation (4). We developed a method to an analyze players' experimental curves in order to determine parameters values. The engagement speed $v_{0}$ is manually determined by video analysis. After the impact, the force is converging towards $F_{0}$ regarding to Equation (3). On the experimental curves, $F_{0}$ is determined by reading the force value after the impact and just before the player is doing is muscular effort to push the scrum machine. Then, the process consists in measuring global characteristics of the curve such as $F_{\text {peak }}$, and enables us to find parameters $A, \beta, k$ and $m$ step by step. In Figure $3 b$, we plot an example of experimental curve on which we applied this method. The dashed orange curve is obtained thanks to Equation (4) and parameters determined by this process. For this example, $A=0.73, \beta=3.1 \times 10^{3} \mathrm{~kg} \cdot \mathrm{s}^{-1}, k=6.1 \times 10^{4} \mathrm{~N} \cdot \mathrm{m}^{-1}, F_{0}=1250 \mathrm{~N}$ and $\mathrm{m}=115 \mathrm{~kg}$. In the model, $m$ is an effective mass which is in motion during the impact. 


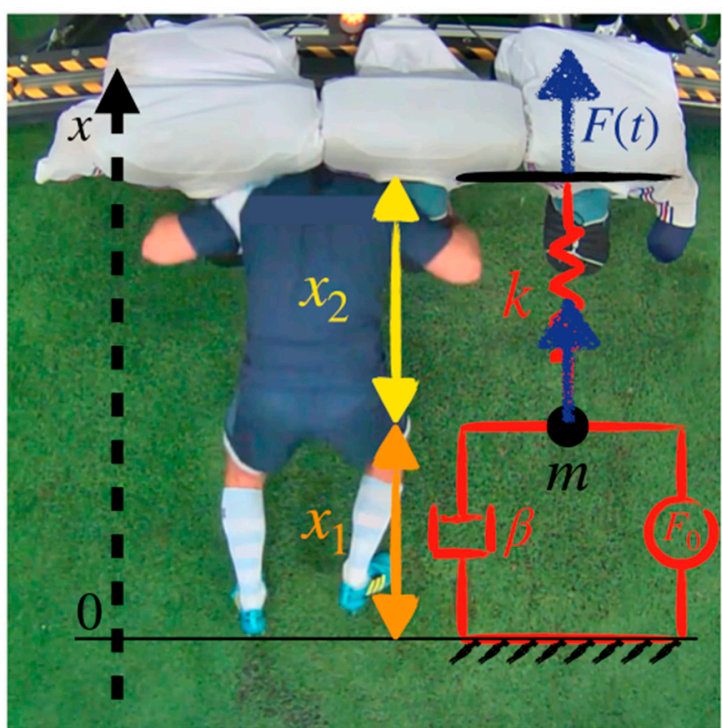

(a)

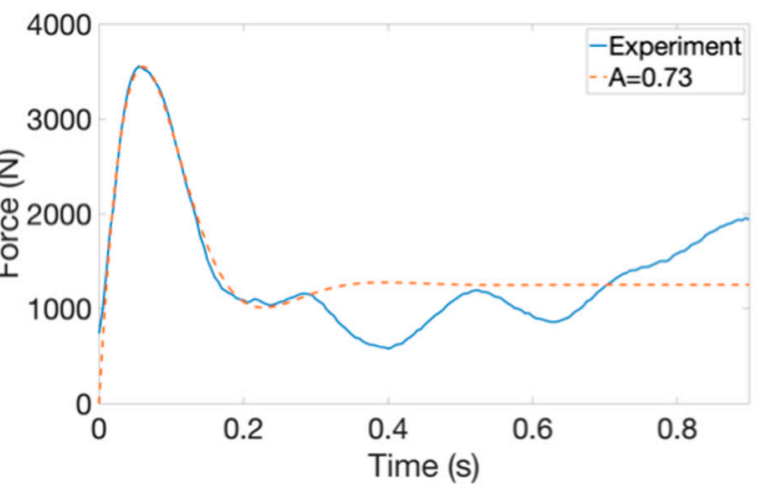

(b)

Figure 3. MacMahon look alike model of a single player against a scrum machine. (a) We introduce the system at the impact time $t_{0}$ with $m, k, \beta, F_{0}$ defined in the main text. The force measured by the scrum machine is called $F$. (b) Compression force time evolution. Comparison between the hooker's experimental curve and the fitting results curve with parameters detailed in the text.

Thanks to this model, we can easily discuss engagement speed and player mass influences on $F_{\text {peak }}$. In Figure 4a, we plot different peak force time evolutions for different masses $m$, which represents player weight influence. In Figure $4 b$, we have the same kind of plot with different engagement speeds. All the other parameters are fixed to the values mentioned earlier. For a single player, we observe that the maximal force at impact $F_{\text {peak }}$ increases when the mass in motion increases, the same tendency that we presented in Section 1 for real scrums. This evolution is quasi-linear. We also observe the increase of $F_{\text {peak }}$ with the engagement speed. As the player mass is difficult to control and has shown in past to constantly increased, we understand that engagement speed is a key parameter to control the compression force peak and to reinforce players' safety.

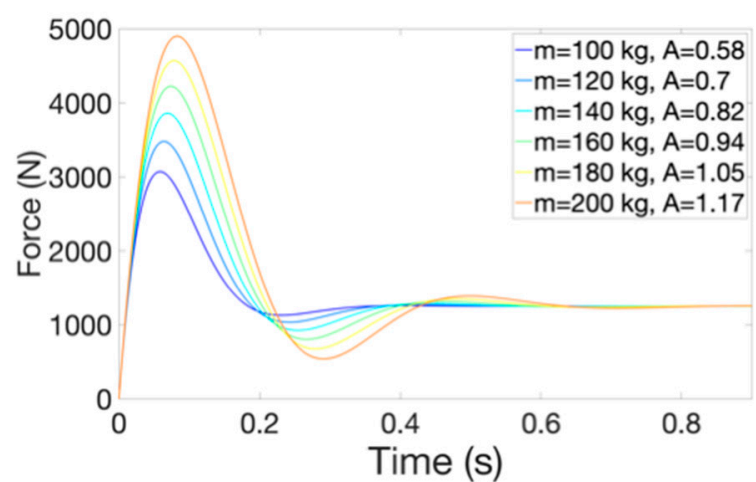

(a)

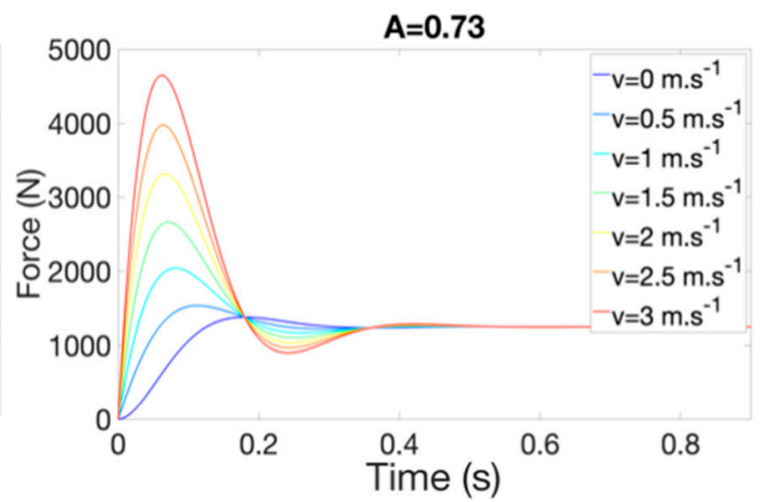

(b)

Figure 4. Compression force time evolution with $\quad \beta=3.1 \times 10^{3} \mathrm{~kg} \cdot \mathrm{s}^{-1}, k=6.1 \times 10^{4} \mathrm{~N} \cdot \mathrm{m}^{-1}, F_{0}=$ $1250 \mathrm{~N}$. (a) Influence of mass $\mathrm{m}$ with $v_{0}=2.2 \mathrm{~m} \cdot \mathrm{s}^{-1}$ on peak force. (b) Influence of the engagement speed $v_{0}$ with $m=115 \mathrm{~kg}$. We observe that the peak force increases both with engagement speed and mass.

\section{Conclusions}

As the weight of rugby players has constantly increased these last decades, we understand the evolutions of the scrum engagement process: by reducing engagement speed, which plays a main 
role in $F_{\text {peak }}$ value, we observe a decrease in peak compression force applied by players. The featured model, which simulates one player pushing against a scrum machine, describes the same influences of player mass and initial speed on $F_{\text {peak }}$. The perspectives of this work is to use this model to determine the stiffness and damping coefficient for different players professional and nonprofessional. Finally, we will implement several units of this model to simulate a complete scrum.

Acknowledgments: The study was funded by Racing 92. We would like to thank Rugby French Federation for welcoming players, staff and scientists. We also want to thank the Racing 92 team's staff and the players for their participation and motivation.

Conflicts of Interest: The authors declare no conflict of interest. The funding sponsors had no role in the design of the study; in the collection, analyses, or interpretation of data; in the writing of the manuscript, and in the decision to publish the results.

\section{References}

1. Laws of the Game Rugby Union. Available online: https://laws.worldrugby.org/?law=19\&amends= off\&language $=\mathrm{EN}$ (accessed on 10 February 2020).

2. Scher, A.T. Rugby injuries to the cervical spinal cord. S. Afr. Med. J. 1977, 51, 473-475.

3. Swaminathan, R.; Williams, J.M.; Jones, M.D.; Theobald, P.S. A kinematic analysis of the spine during rugby scrummaging on natural and synthetic turfs. J. Sports Sci. 2016, 34, 1058-1066.

4. Wetzler, M.J.; Akpata, T.; Laughlin, W.; Levy, A.S. Occurrence of cervical spine injuries during the rugby scrum. Am. J. Sports Med. 1998, 26, 177-180.

5. Milburn, P.D. The kinetics of rugby union scrummaging. J. Sports Sci. 1990, 8, 47-60.

6. Olds, T. The evolution of physique in male rugby union players in the twentieth century. J. Sports Sci. 2001, $19,253-262$.

7. Hill, N.E. Changes in northern hemisphere male international rugby union players' body mass and height between 1955 and 2015. BMJ Open Sport Exerc. Med. 2018, 4, 1.

8. Quarrie, K.L.; Wilson, B.D. Force production in the rugby union scrum. J. Sports Sci. 2000, 18, 237-246.

9. Preatoni, E.; Stokes, K.A.; England, M.E.; Trewartha, G. Engagement techniques and playing level impact the biomechanical demands on rugby forwards during machine-based scrummaging. Br. J. Sports Med. 2015, 49, 520-528.

10. Cazzola, D.; Preatoni, E.; Stokes, K.; England, M.E.; Trewartha, G. A modified prebind engagement process reduces biomechanical loading on front row players during scrummaging: A cross-sectional study of 11 elite teams. Br. J. Sports Med. 2015, 49, 541-546.

11. Gianotti, S.; Hume, P.A.; Hopkins, W.G.; Harawira, J.; Truman, R. Interim evaluation of the effect of a new scrum law on neck and back injuries in rugby union. Br. J. Sports Med. 2008, 42, 427-430.

12. Preatoni, E.; Stokes, K.A.; England, M.E.; Trewartha, G. The influence of playing level on the biomechanical demands experienced by rugby union forwards during machine scrummaging. Scand. J. Med. Sci. Sports 2013, 23, e178-e184.

13. Preatoni, E.; Wallbaum, A.; Gathercole, N.; Coombes, S.; Stokes, K.A.; Trewartha, G. An integrated measurement system for analysing impact biomechanics in the rugby scrum. J. Sports Eng. Technol. 2012, 226, 266-273.

14. McMahon, T.A. Muscles, Reflexes and Locomotion; Princeton University Press: Princeton, NJ, USA, 1984. 